\title{
Criterios para el Diseño de un Programa Piloto de Justicia Restaurativa Orientado a la Atención de Casos de Violencia Intrafamiliar en el Centro de Atención Integral a Víctimas de Violencia Intrafamiliar (CAVIF) de la Fiscalía General de la Nación en la Ciudad de Bogotá (Colombia)
}

\section{Criteria to Design a Restorative Justice Test Program for Intra-familiar Violence Attention at the Center of Integral Attention to Victims of Intra- familiar Violence (CAVIF) of the General Office of the Public Prosecutor of the Nation at the City of Bogota (Colombia)}

Leonardo Rodríguez, Andrea Padilla, Luz Stella Rodríguez y Fernando Díaz Grupo de Investigación Psicológia Jurídica y Forense: Retos y Perspectivas

Resumen. El presente estudio define los criterios para el diseño de un programa piloto de Justicia Restaurativa orientado a la atención de casos de violencia intrafamiliar en el Centro de Atención Integral a Víctimas de Violencia Intrafamiliar (CAVIF) de la Fiscalía General de la Nación. Los criterios que se exponen son el producto de un trabajo conceptual y metodológico aplicado a la recolección, sistematización y análisis de la información recopilada con base en un diseño de investigación descriptivo exploratorio. Para el estudio se tuvo una muestra intencional de participantes, integrada por 20 usuarios y 18 profesionales del CAVIF, a quienes se les administraron entrevistas a profundidad diseñadas a partir de categorías previamente definidas. En el presente artículo se describe una serie de necesidades del contexto institucional, profesional y de los propios usuarios y funcionarios del sistema, las cuales permiten comprender las condiciones necesarias para proponer unos lineamientos generales para la formulación de un programa piloto acorde con la ley vigente en Colombia. Los resultados del estudio permiten señalar la importancia de llevar a cabo procesos de capacitación en Justicia Restaurativa con los funcionarios responsables de dar trámite a los conflictos de violencia intrafamiliar en el CAVIF. Como aporte final se proponen criterios generales para el diseño y la implementación del programa piloto y de programas de asistencia a víctimas.

Palabras clave: Justicia Restaurativa, victimología, violencia intrafamiliar.

La correspondencia sobre este artículo deberá dirigirse al primer

autor al e-mail: leocely@gmail.com 


\begin{abstract}
This study sets the criteria to design a restorative justice test program for the attention of intra familiar violence cases at the Center of Integral Attention to Victims of Intra Familiar Violence (CAVIF) of the nation's General Public Prosecutor. The exposed criteria is the result of a conceptual and methodological work applied to the collection, systematization and analysis of information collected through a descriptive exploratory research design. An intentional sample of participants was used, 20 users and 18 workers from the CAVIF, whom were deeply interviewed with previous definited categories. At this work, needs from the institutional scope, professional and from the users and workers are described, that allows to understand the needed conditions to propose general lines to ordenate a test program acording to the effective law at Colombia. Results allow to point the matter of developing qualification procedures in restorative justice with workers at charge of intrafamiliar violence conflicts at the CAVIF. As a final contribution, general criteria to the design and implementation of test programs and victims' assistance programs is proposed
\end{abstract}

Key words: restorative justice, victimology, intra familiar violence.

\section{Antecedentes}

En las últimas décadas los diferentes movimientos y asociaciones de ayuda a las víctimas han representado una nueva fuerza y una realidad en la democracia, que condicionan moralmente la política criminal hacia la consecución de la convivencia pacífica (Sampedro, 2002). En este sentido se busca que la verdad sea fruto de leyes pluralistas y democráticas, aplicadas humanamente, donde se pretende establecer la verdad, procurando por una sanción justa, una compensación generosa a las víctimas, sanar la memoria de las victimas acompañándolas en su sufrimiento como la forma para superar el pasado y trascender el conflicto en busca de la reconciliación. De acuerdo con estos enunciados, en el ámbito internacional cada día se hace imperioso prestar atención preferente a las víctimas especialmente en campos como el Derecho Penal y Procesal (Berinstain, Mesutti y Sampedro, 2001). Así se ha consagrado expresamente en importantes documentos, entre los cuales se encuentran la Declaración 40/34 de la Organización de las Naciones Unidas (en adelante ONU); el Informe del Décimo Congreso de la ONU sobre prevención del delito y tratamiento del delincuente de 19 de julio de 2000; la Declaración de Viena sobre la delincuencia y la justicia: frente a los retos del siglo XXI de 15 de abril de 2000; el documento de trabajo denominado "Delincuentes y Víctimas: responsabilidad y equidad en el proceso de justicia penal" preparado por la secretaría de la ONU para el Décimo Congreso sobre prevención del delito y tratamiento del delincuente de 15 de diciembre de 1999; la Recomendación del Comité de Ministros del Consejo de Europa; la comunicación (en adelante COM) (99) 349 final de 14 de julio de 1999 de la Comisión Europea ' la Decisión Marco del Consejo de la Unión Europea de 15 de marzo de 2001; el «Libro Verde» sobre Indemnización a las víctimas de delitos de la Comisión Europea, entre otros muchos.

El replanteamiento de las prácticas de administración de justicia a nivel internacional, la implementación de un sistema penal acusatorio en Colombia (Ley 906 de 2004) y las nuevas disposiciones en derecho de familia, entre otros factores, han tenido efectos como la ampliación de la institucionalidad y el desarrollo de una mayor oferta pública alternativa y complementaria al sistema tradicional de justicia. La ampliación de la oferta de mecanismos alternativos al sistema penal retributivo, impulsada como parte de una política nacional orientada al resarcimiento de los derechos de las víctimas, al empoderamiento de la comunidad y a la generación de alternativas a la judicialización de los conflictos, ha estado acompañada, así mismo, de una institucionalidad integrada de apoyo representada en la creación de nuevas figuras y servicios que deben estar acordes a los planteamientos y requerimientos del nuevo paradigma restaurativo. Al igual que otros conflictos, la violencia intrafamiliar ha entrado a hacer parte de esta nueva concepción de justicia, por lo cual las instituciones correspondientes han entrado a diseñar e implementar programas alternativos. 
En este sentido, la Fiscalía General de la Nación ha creado el Centro de Atención Integral a Víctimas de Violencia Intrafamiliar (CAVIF), con el fin de "restaurar familias en situación de violencia intrafamiliar y sexual, generando una sinergia entre la infraestructura de justicia ya creada y [el] CAVIF" (Fiscalía General de la Nación, Acuerdo 123 de 2004). De acuerdo con el documento base de la entidad, el servicio brindado en la institución "es un modelo de justicia restaurativa tanto en el sistema mixto como en el Sistema Acusatorio. No sólo se persigue al agresor, sino que también se apoya a la víctima y a su núcleo familiar para superar las secuelas de una agresión". De esta manera, se asume que "la justicia restaurativa permite el restablecimiento pleno de los derechos de las víctimas porque se detiene la violencia, se aleja al agresor y se brindan medidas de protección" (Fiscalía General de la Nación).

Sin embargo, la alternativa que hoy aporta el CAVIF continúa sin adecuarse a los planteamientos y principios de la justicia restaurativa (más próxima a la figura de la conciliación que establecía la Ley 600 de 2000), aun cuando contemple una serie de recursos (talleres, seminarios, manejo terapéutico y seguimiento) para brindar una atención más integral a su población objetivo. De allí, es posible afirmar que aún no se ha hecho efectiva la implementación de programas de justicia restaurativa en los términos que establece la Ley 906 de 2004 (arts. 518 a 527), debido probablemente a la adopción reciente del mecanismo y al carácter novedoso del paradigma, así como a la falta de procesos pedagógicos dirigidos a los funcionarios a quienes corresponde su implementación.

\section{La Justicia Restaurativa. Marco teórico y normativo}

En Colombia, la implementación de programas de justicia restaurativa se ha venido haciendo efectiva a partir de la normatividad de base que define y establece las nuevas formas de aplicación de justicia. En el país, el término justicia restaurativa fue consagrado con la aprobación del Acto Legislativo 03 de 2002, en el cual se establece que la Fiscalía General de la Nación, en ejercicio de sus funciones, debe "velar por la protección de las víctimas, los jurados, los testigos y demás intervinientes en el proceso penal. La ley fijará los términos en que podrán intervenir las víctimas en el proceso penal y los mecanismos de justicia restaurativa" (art. 250, numeral 7).

Posteriormente, esta disposición fue desarrollada en la Ley 906 de 2004 que expidió el nuevo Código de Procedimiento Penal, en la que se define la justicia restaurativa como,

“(...) todo proceso en el que la víctima y el imputado, acusado o sentenciado participan conjuntamente de forma activa en la resolución de cuestiones derivadas del delito en busca de un resultado restaurativo, con o sin la participación de un facilitador. Se entiende por resultado restaurativo el acuerdo encaminado a atender las necesidades y responsabilidades individuales y colectivas de las partes y a lograr la reintegración de la víctima y del infractor en la comunidad, en busca de la reparación, la restitución y el servicio a la comunidad". (art. 518).

Esta Ley contempla tres mecanismos de justicia restaurativa, a saber: la conciliación preprocesal, la conciliación en el incidente de reparación integral y la mediación (art. 521); así como seis reglas generales (art. 520) para la implementación de los programas de justicia restaurativa: 1) consentimiento libre y voluntario de la víctima y el imputado, acusado o sentenciado de someter el conflicto a un proceso restaurativo, 2) los acuerdos que se alcancen deberán contener obligaciones razonables y proporcionadas con el daño ocasionado por el delito, 3) la participación del imputado, acusado o sentenciado no se utilizará como prueba de admisión de culpabilidad en procedimientos jurídicos ulteriores, 4) el incumplimiento de un acuerdo no deberá utilizarse como fundamento para una condena o para la agravación de la pena, 5) los facilitadores deben desempeñar sus funciones de manera imparcial y velarán porque la víctima y el imputado, acusado o sentenciado actúen con mutuo respeto, y 6) la víctima y el imputado, acusado o sentenciado tendrán derecho a consultar a un abogado.

Sin embargo, en el contexto de familia, la Ley 906 de 2002 contempla la violencia intrafamiliar 
como uno de los delitos que requieren querella (art. 229) ${ }^{1}$. No obstante, la aplicación del principio de oportunidad $^{2}$ abre a los sujetos activos y pasivos involucrados en un delito de familia, la posibilidad de acordar la reparación civil y llegar a un acuerdo antes de iniciar un proceso judicial penal. Con este fin, el fiscal puede acudir a los mecanismos de suspensión del procedimiento a prueba o interrupción de la actuación penal, con el propósito de verificar el cumplimiento de las condiciones convenidas para dar aplicación a la renuncia y solución al caso por la vía de la justicia restaurativa.

La justicia restaurativa es un paradigma que confronta los sistemas tradicionales, punitivo y rehabilitador, a la vez que promueve la reparación del daño causado por el delito. Hace énfasis en la dimensión del perjuicio antes que en la dimensión de la trasgresión de una norma jurídica (sistema punitivo) o de las necesidades del infractor (sistema rehabilitador), con lo cual reconoce que "la función principal de la reacción social no es ni castigar, ni tratar, sino crear las condiciones para que una reparación y/o una compensación razonable de los perjuicios se puedan realizar" (Walgrave, 1999; Walgrave, L. Y Bazemore, G., 1999).

La Confraternidad Carcelaria Internacional (2005) define la justicia restaurativa como una teoría de justicia que enfatiza en la reparación del daño causado o presentado por una conducta delictiva, cuyos objetivos se alcanzan a través de procesos cooperativos que incluyan a todos los interesados. En esta medida, se destaca por la participación activa de las partes involucradas, con el fin de que sean ellas mismas quienes propongan las estrategias de justicia frente al conflicto. A diferencia de los sistemas tradicionales, la justicia restaurativa propende por la responsabilidad del infractor, la reparación de

1 Este artículo ha sido reformado por el artículo 33 de la Ley $1142 / 2007$ en lo referente a las penas.

${ }^{2}$ El principio de oportunidad "es la facultad constitucional que le permite a la Fiscalía General de la Nación, no obstante que existe fundamento para adelantar la persecución penal, suspenderla, interrumpirla o renunciar a ella, por razones de política criminal, según las causales taxativamente definidas en la ley, con sujeción a la reglamentación expedida por el Fiscal General de la Nación y sometido a control posterior de legalidad ante el juez de garantías (...). Por medio de la aplicación del principio de oportunidad, el Estado finalmente renuncia a investigar una conducta con características de delito o a la acusación de los presuntos responsables (...)" (Fiscalía General de la Nación, 2005: 167). la víctima y la participación de la comunidad; de esta manera, pretende afrontar los perjuicios sociales, psicológicos y relacionales, trascendiendo la mera respuesta a los daños materiales y físicos causados por la conducta delictiva. Bajo esta perspectiva, "la ambición maximalista de la justicia restaurativa obliga a concebir una relación coherente entre las partes, los procesos y las prácticas restaurativas, (...) y el Estado social de derecho y sus instituciones" (Berinstain 1998), puesto que ambos "tienen misiones complementarias en la reparación de las consecuencias de un delito" (Van Ness y Heetderks Strong, 1997). En efecto, si bien la justicia restaurativa otorga prioridad a las respuestas provenientes del exterior del sistema judicial y busca "vías alternativas" para promover la primacía de la comunidad, esto no implica la exclusión de sanciones impuestas desde el aparato judicial.

Berinstain (1998) resume los rasgos fundamentales del modelo restaurativo, en comparación con el modelo retributivo, en los siguientes aspectos (ver cuadro página siguiente):

De acuerdo con García-Pablos (1999), a través del modelo de justicia restaurativa se busca un modelo integrador de respuesta al fenómeno social del delito que ofrezca una imagen de justicia más humana; una justicia más legal que profesional, próxima al ciudadano, de marcado perfil comunitario, pacificadora, comunicativa e integradora. Una justicia que comprenda los conflictos desde dentro y trate de buscar soluciones a los mismos sin imponerlas; constructiva y no represiva. Que se sintonice con los valores éticos, con el sentido común del ciudadano, con la experiencia humana y comunitaria, sin refugiarse en formalismos y exigencias utilitaristas. Todo ello, mediante procedimientos des-formalizados, flexibles y operativos que faciliten la negociación, el tratamiento del conflicto y su solución satisfactoria sin perjuicio del control, y garanticen, por supuesto, los derechos fundamentales de los implicados.

La investigación y experiencia internacional aportan un marco teórico y práctico fundamental para avanzar en el diseño de programas de justicia restaurativa y en la aplicación de sus principios, así como para establecer criterios de viabilidad y condiciones para su aplicabilidad en distintos escenarios 


\section{Modelo retributivo}

El delito es la infracción a la norma penal del Estado.

Se centra en el reproche, la culpabilidad, mirando al pasado, a lo que el delincuente hizo.

Se reconoce una relación de contrarios, de adversarios, que vencen y someten al enemigo en un proceso normativo legal

El castigo es la consecuencia natural, dolorosa, que también conlleva o pretende la prevención general y especial.

El delito se percibe como un conflicto (ataque) del individuo contra el Estado. Se menosprecia su dimensión interpersonal y conflictiva.

El daño que padece el sujeto pasivo del delito se compensa con (reclama) otro daño al delincuente.

Se margina a la comunidad (y a las víctimas) y se la ubica de forma abstracta en el Estado.

Se promueve y se fomenta, el talante competitivo y los valores individuales.

La sanción es la reacción del Estado contra el delincuente. Se ignora a la víctima y el delincuente permanece pasivo.

El deber del delincuente es cumplir (sufrir) la pena.

El delincuente no tiene responsabilidad en la solución del problema.

El delito se define a tenor de la formulación legal, sin tomar en consideración las dimensiones morales, sociales, económicas y políticas.

El delincuente tiene una deuda con el Estado y la sociedad en abstracto.

El estigma del delito es imborrable.

No se fomenta el arrepentimiento ni el perdón.

La justicia está exclusivamente en manos de profesionales gubernamentales.

Cuadro Resumen Antonio Berinstain (1998)

de la administración de justicia. El amplio desarrollo internacional que ha tenido la justicia restaurativa en los últimos treinta años, ha generado una serie de documentos jurídicos que promueven y regulan la implementación de los diferentes mecanismos y programas en delitos de diversa gravedad. El entendimiento de que la justicia restaurativa ha pasado a ser una importante alternativa a los procesos de enjuiciamiento en la justicia penal ha favorecido la

\section{Modelo restaurativo}

El delito es la acción que causa daño a otra persona.

Se centra en la solución del problema, en la responsabilidad y obligaciones mirando al futuro.

Se establece un diálogo y una negociación normativa que imponga al delincuente una sanción restauradora.

La solución del conflicto está en la reparación como un medio de restaurar ambas partes, víctima y delincuente. Tiene como meta la reconciliación.

El delito se reconoce como un conflicto interpersonal. Se reconoce el valor del conflicto.

Se pretende lograr la restauración del daño social.

La comunidad se convierte en catalizador de un proceso restaurativo versus el pasado.

Se incentiva la reciprocidad.

Se reconoce el papel de la víctima y el papel del delincuente, tanto en el problema (delito) como en su solución. Se reconocen las necesidades y los derechos de la víctima. Se anima al delincuente a responsabilizarse.

Se define la responsabilidad del delincuente como la comprensión del impacto de su acción y el compromiso de reparar el daño.

El delincuente tiene responsabilidad en la solución del conflicto.

El delito se entiende en todo su contexto moral, social, económico y político.

A la víctima se la reconoce la deuda y la responsabilidad.

El estigma del delito puede borrarse por la acción reparadora/restauradora.

Se procura el arrepentimiento y el perdón.

La respuesta al delito se crea desde los propios protagonistas. implementación de programas en sistemas de justicia altamente variados.

$\mathrm{El}$ auge de los programas alternativos de administración de justicia en el campo de familia, ha obedecido a la necesidad de desjudicializar y descriminalizar los conflictos familiares que admitan vías alternas de tramitación. La importancia otorgada a los procesos restaurativos en este campo ha radicado en el estatus otorgado a la familia como 
institución socializadora de base que, por dinámicas propias o mediante facilitadores, debe generar mecanismos de concertación que incidan positivamente en las relaciones interpersonales y prevengan desórdenes en el grupo social y formas violentas o delictivas de relación. En este sentido, la violencia intrafamiliar ha sido identificada como un factor de riesgo desde una perspectiva de prevención de la criminalidad urbana, por lo cual los gobiernos han priorizado estrategias que permitan hacer frente a la dimensión pública del conflicto y contrarrestar el resquebrajamiento de la convivencia (Walker, L., 2007).

\section{Método}

El estudio se basó en un diseño de tipo descriptivo exploratorio. Para la recolección de la información se empleó una metodología de tipo cualitativo.

\section{Muestra}

Se contó con una muestra intencional integrada por veinte usuarios que asistieron al CAVIF por situaciones de violencia intrafamiliar y 18 funcionarios -entre fiscales, técnicos judiciales, secretarios judiciales, asistentes judiciales y asistentes de fiscal- empleados del CAVIF en el momento de la investigación.

\section{Instrumento}

La recolección de información se realizó a través de dos entrevistas semiestructuradas -para usuarios y fiscales- diseñadas específicamente para el estudio.

\section{Categorías}

Las entrevistas se elaboraron a partir de categorías previamente definidas y específicas para funcionarios y usuarios. Con base en ellas se efectuó el análisis de los resultados.

\section{Categorías funcionarios}

Categoría 1. Conocimiento y experiencia institucional. Se refiere al conocimiento y la experiencia de los funcionarios en materia de violencia intrafamiliar y justicia restaurativa desde el punto de vista teórico y conforme al marco normativo que rige su implementación en el CAVIF.

Categoría 2. Conocimientos sobre principios de justicia restaurativa. Se refiere al conocimiento que tienen los funcionarios sobre los principios de la justicia restaurativa.

Categoría 3. Conocimientos sobre programas de justicia restaurativa. Se refiere al conocimiento que tienen los funcionarios sobre los programas y mecanismos de la justicia restaurativa; particularmente, aquellos implementados en casos de violencia intrafamiliar.

Categoría 4. Conocimientos sobre procedimientos de justicia restaurativa. Se refiere al conocimiento que tienen los funcionarios sobre los procedimientos generales de la justicia restaurativa (programas y mecanismos).

Categoría 5. Competencias profesionales. Se refiere a las competencias (personales, sociales y profesionales) que, a juicio de los funcionarios, deben tener las personas que intervengan en procesos de justicia restaurativa en casos de violencia intrafamiliar.

Categoría 6. Recursos institucionales. Se refiere a los recursos institucionales (humanos, logísticos y económicos) que, a juicio de los funcionarios, se requieren para implementar programas de justicia restaurativa en casos de violencia intrafamiliar.

\section{Categorías usuarios}

Categoría 1. Conocimiento institucional. Se refiere a la información con la que cuentan los usuarios sobre la Fiscalía General de la Nación y el Centro de Atención a Victimas de Violencia Intrafamiliar (CAVIF), adquirida a través de los profesionales y los programas que se ofrecen a la comunidad.

Categoría 2. Historia de la violencia intrafamiliar. Se refiere a la narración y caracterización que hacen los usuarios del ó de los conflictos que han vivido al 
interior del núcleo familiar, haciendo énfasis en las circunstancias que lo han llevado a recurrir al CAVIF.

Categoría 3. Expectativas de solución frente al conflicto. Narración que realizan los usuarios respecto a la posible solución del conflicto familiar y las expectativas de intervención del CAVIF.

Categoría 4. Conocimientos sobre procedimientos de justicia restaurativa. Se refiere al conocimiento que tienen los usuarios sobre los procedimientos generales de la justicia restaurativa (programas y mecanismos).

Categoría 5. Percepción sobre el daño causado. Descripción que realizan los usuarios acerca de las consecuencias físicas, psicológicas, sociales y morales que ha tenido en ellos la violencia intrafamiliar.

Categoría 6. Participación en la solución del conflicto. Se refiere a la necesidad y voluntad de los usuarios para asumir los principios y características de los programas de justicia restaurativa que puede ofrecer el CAVIF.

\section{Resultados}

A Continuación se presentará los resultados más importantes del estudio, donde se encontrará, las categorías deductivas e inductivas de la investigación, tanto de profesionales como usuarios que participaron pertenecientes al Centro de Atención a Víctimas de Violencia Intrafamiliar (CAVIF). (Ver Cuadros 1 y 2).

Una vez identificadas las percepciones de los funcionarios y usuarios del CAVIF sobre la justicia restaurativa, sus implicaciones y procedimientos, y tenidas en cuenta las representaciones de usuarios $\mathrm{y}$ funcionarios sobre la violencia intrafamiliar, entre otros temas conexos como la institucionalidad, las medidas punitivas y algunos de orden más subjetivo como la vivencia de la violencia por parte de las víctimas del delito, se proponen algunos lineamientos para la implementación de un programa piloto de justicia restaurativa en el CAVIF. Aunque la propuesta se circunscribe en un escenario particular y se plantea frente a una problemática específica, se espera que sus resultados sirvan de insumo para el diseño de programas de justicia restaurativa en otros escenarios de administración de justicia.

\section{Propuesta. Criterios para un programa piloto de Justicia Restaurativa orientado a casos de violencia intrafamiliar}

1. Estrategia piloto: Dada la novedad de la justicia restaurativa en Colombia y su reciente ingreso en el sistema de investigación judicial, es importante implementar programas piloto involucrando a las poblaciones objetivo, con el fin de identificar aspectos fundamentales como los criterios de participación en el programa, los mecanismos de participación de la comunidad, los posibles acuerdos de reparación y las estrategias de seguimiento y apoyo comunitario, inherentes a la implementación del mecanismo.

2. Capacitación a funcionarios: Debido al desconocimiento casi generalizado que expresan los funcionarios acerca de los principios y procedimientos de la justicia restaurativa, es fundamental que un proyecto piloto abarque una primera fase de capacitación con los profesionales del CAVIF que estarían directamente a cargo de su implementación y conducción, y con los funcionarios de las instituciones conexas que apoyarían su desarrollo desde otros frentes (acuerdos de reparación, restablecimiento de derechos, apoyo social a las víctimas).

3. Información a las víctimas: Debido al desconocimiento que expresan los usuarios acerca de las alternativas de abordaje jurídico-penal del delito, sus derechos y efectos jurídicos de los acuerdos, es importante elaborar dispositivos de información y estrategias de comunicación para dar a conocer los objetivos de los programas de justicia restaurativa que puede ofrecer el CAVIF, sus efectos, implicaciones, procedimientos y fundamentos. También es importante desarrollar propuestas acerca de cómo la conciliación podría adoptar los principios de la justicia restaurativa para lograr acuerdos efectivos y procesos adecuados de 
Cuadro 1. Resultados funcionarios

\section{Categorías $\quad$ Funcionarios}

Conocimiento y experiencia institu- En cuanto a la aplicación de los principios de justicia restaurativa, los funcionarios, en su mayoría, consideran cional que ésta se lleva a cabo a través de la conciliación, de la aplicación del principio de oportunidad y de la remisión al servicio de psicología. En este sentido, entienden la justicia restaurativa como el procedimiento dirigido a restablecer los derechos de las víctimas, a buscar una indemnización económica, a la presentación de solicitud de perdón por parte del victimario y a la iniciación de un proceso terapéutico.

Conocimiento sobre los principios de Los funcionarios del CAVIF no cuentan con suficiente conocimientos sobre la justicia restaurativa en términos Justicia Restaurativa conceptuales. En su gran mayoría, los usuarios pretenden que la institución realice acciones de diverso orden para que cese la violencia y el victimario cambie su forma de actuar. Otros, por el contrario, consideran que los usuarios buscan castigar al victimario a través de la denuncia ante las autoridades.

Conocimiento sobre programas de La mayoría de funcionarios no sabe en qué consiste un programa de justicia restaurativa; algunos de ellos conJusticia Restaurativa sideran que se trata de la realización de las conciliaciones y las consecuencias legales de los acuerdos que allí se presentan, tales como: indemnización, perdón y compromiso con la víctima de no repetir la conducta. En su mayoría, opinan que a la víctima se le puede habilitar y dar protagonismo a través de acciones como la asistencia psicológica, la información adecuada y un trato amable y coherente con la situación que se denuncia. Piensan que los usuarios deben participar de manera activa en la solución de su conflicto, proporcionando a los Fiscales las posibles soluciones que se puedan implementar.

Apoyo del estado en programas de Para los profesionales del CAVIF, la falta apoyo por parte del Estado para implementar programas de justicia Justicia Restaurativa restaurativa y brindar mayor asistencia psicológica y social con el fin de ampliar la participación de otras entidades, hace necesario un seguimiento más riguroso de este proceso que permita medir la reincidencia de los victimarios y verificar el cumplimiento de los acuerdos. Piensan que este último aspecto incide en la presentación continua de conciliaciones que no resuelven el conflicto, sino que, por el contrario, lo mantienen en un círculo vicioso, determinando la poca credibilidad de los usuarios respecto a las instituciones.

Participación de la comunidad en programas de Justicia Restaurativa

En cuanto a la participación de la comunidad, los funcionarios del CAVIF consideran que hace falta más información sobre las alternativas de participación, los diferentes programas de la Alcaldía y la importancia de denunciar estos actos violentos. Opinan que no se aborda esta problemática desde el punto de vista macro, sino que se queda en la esfera de lo familiar.

Competencias profesionales para lle- Para los profesionales del CAVIF, el personal que trabaje con un enfoque enmarcado en la justicia restaurativa var a cabo programas de Justicia debe tener una capacidad de comprensión y compromiso con los usuarios y la problemática que allí se atiende. Restaurativa Consideran necesaria una capacitación especial para atender este tipo de conflictos desde una perspectiva humana, ya que por su condición de abogados, según señalan, no han sido preparados para ello. En su opinión, hay una necesidad de recibir capacitación en áreas como asistencia social, negociación y resolución de conflictos.

Funcionarios que deben participar en En general, los funcionarios señalan que la naturaleza de la violencia intrafamiliar hace imprescindible la parProgramas de Justicia Restaurativa ticipación de psicólogos, trabajadores sociales, representantes de la Personería y la Procuraduría, la Policía, la Defensoría Pública, Bienestar Familiar y las Comisarías de Familia; así como la conformación de equipos interdisciplinarios que posibiliten la acción conjunta para restablecer los derechos y reparar a las víctimas. En suma, la realización de un trabajo intersectorial, interinstitucional e interdisciplinario.

Recursos para llevar a cabo progra- Para el cumplimiento de su tarea, los Fiscales señalan que hacen falta recursos y herramientas tales como: insmas de Justicia Restaurativa talaciones adecuadas, instrumentos tecnológicos, personal capacitado, espacio físico para la realización de talleres y la ejecución de entrevistas donde se permita mantener la privacidad. Así mismo, mencionan la falta de compromiso de las Entidades Promotoras de Salud (EPS) y del apoyo de las instituciones relacionadas con la problemática de familia, ya que actualmente sólo se cuenta con un defensor de familia.

Justicia Restaurativa y violencia Los funcionarios del CAVIF consideran que la violencia intrafamiliar es un problema fundamentalmente culdoméstica tural y social en el que intervienen, además, factores como lo económico, la condición social y la educación. Afirman que este delito les genera cuestionamientos sobre la eficacia de la ley y sobre la asistencia psicológica y social que allí se brinda para solucionar esta problemática, puesto que, a su juicio, la solución no es de naturaleza punitiva, sino de orden preventivo. 
Cuadro 2. Resultados funcionarios

Categorías de estudio

Conocimiento institucional

Historia de Violencia doméstica

Percepción ante de las instituciones.

Justicia Restaurativa y prisión

\section{Usuarios de CAVIF}

Los usuarios evidencian un desconocimiento frente a las funciones y competencias de la Fiscalía General de la Nación y el CAVIF; en algunos casos, refrieren información incompleta suministrada por terceros no cualificados. En términos generales, es posible afirmar que los usuarios poseen un conocimiento equivocado y no fundamentado sobre la institución.

Los usuarios narran situaciones de violencia caracterizadas por desigualdad de poder en la relación, continuidad en el tiempo y la sensación de amenaza a su integridad. Describen ciclos de violencia marcados por intentos de solución fallida del conflicto, compromisos de cambio, expresiones de arrepentimiento e intervención de terceros como familiares, instituciones y asesoría profesional.

Los usuarios evidencian una desesperanza ante la solución del conflicto por medio de instituciones tradicionales como las Comisarías de Familia y de acciones como la conciliación. Otras respuestas se asocian con la búsqueda de apoyo y protección y la cesación de los episodios de maltrato. En su mayoría, los usuarios mencionan que quedarían satisfechos frente al conflicto si hubiese restricciones para el victimario (para acercarse a la víctima o a los demás miembros de la familia), cumplimiento de las obligaciones económicas y modificación del comportamiento del agresor.

En relación con la pena de prisión como posible castigo para el delito de violencia intrafamiliar, los usuarios expresan acuerdo, en su mayoría, sólo cuando se han implementado otros mecanismos de solución y ninguno ha sido eficaz. Finalmente, asocian la pena de prisión con sentimientos de resentimiento con el agresor y pocas probabilidades de cambio.

Conocimiento sobre procedimientos Se hace evidente un desconocimiento de los usuarios frente a los procedimientos generales de los programas y de Justicia Restaurativa mecanismos de justicia restaurativa. Asocian la reparación con términos como: arreglar, remediar, cambiar, reponer y, en menor frecuencia, pagar, beneficios y reconstruir. Así mismo, asocian la percepción del daño con: humillante, grave, psicológico, irreparable, miedo y dolor. Destacan dentro del proceso el conocimiento de la verdad de los hechos, y como sintomatología a nivel psicológico la ansiedad, la depresión y la baja autoestima.

Percepción del conflicto

En cuanto a la responsabilidad en el conflicto, la respuesta más frecuente es la admisión de responsabilidad de víctima y victimario en la presentación del conflicto. Los usuarios relacionan la admisión de responsabilidad con: permitir, tolerar y no hacer nada ante los hechos de violencia.

La mayoría de ellos considera que la persona con quien tienen el conflicto se siente culpable o responsable. En este sentido, las narraciones se enmarcan en la fase de arrepentimiento del ciclo de violencia en la que el agresor trata de recuperar el equilibrio de la relación por medio de justificaciones, manifestaciones de cariño y promesas de no recaer, con el objetivo de conciliar y continuar con su pareja.

Participación en la solución de los Los usuarios, en su mayoría, estarían dispuestos a reunirse con el agresor en un contexto seguro y estructuraconflictos do, con el objetivo de que suscitar el reconocimiento de su responsabilidad y la terminación del conflicto. Sin embargo, manifiestan que no estarían dispuestos a recibir o solicitar disculpas, asociando estos eventos con anteriores soluciones fallidas al conflicto. Bajo esta perspectiva, consideran que la comunidad podría aportar sólo en el caso de instituciones o personas que tuvieran la función de mediadores, asociando la participación de la comunidad con la pérdida de privacidad.

Participación en la solución de los Manifiestan que están dispuestos a asistir al CAVIF de manera periódica, ante la expectativa de una solución conflictos efectiva al conflicto centrada en el aspecto legal. En las respuestas, se evidencia que algunas de las dificultades para la asistencia son los horarios y los compromisos laborales.

reparación. Esta información debe hacer énfasis en el carácter reparador (no punitivo) del mecanismo, en la participación voluntaria de los implicados en el delito y en la participación de la comunidad.
4. Información a los agresores de VIF: Esta estrategia de información también debe estar dirigida a los agresores de VIF, haciendo hincapié en sus derechos, condiciones de participación voluntaria, posibles estrategias de resarcimien- 
to o acuerdos de reparación, participación de la comunidad y objetivos principales de la Justicia Restaurativa.

5. La comunidad: Teniendo en cuenta la importancia de la participación de la comunidad en los procesos de justicia restaurativa y la idea que aún prevalece de la VIF como un asunto privado, es importante adelantar procesos de información a la comunidad acerca de la función simbólica, reparadora y de control social informal que cumple en los procedimientos de justicia. La capacitación de facilitadores comunitarios (maestros, líderes, promotores de salud, jueces de paz, entre otros) capaces de orientar a víctimas y agresores y coordinar la participación de la comunidad, debe hacer parte de esta estrategia.

\section{Criterios para el diseño y la implementación del programa piloto}

De acuerdo con los resultados de la investigación, el diseño y la implementación del programa piloto debe tener en cuenta los siguientes criterios: a) Orientación psicojurídica: Generar espacios informativos para víctimas y agresores de VIF que deseen hacer parte del programa. En este espacio se debe suministrar toda la información relacionada con el mecanismo, sus principios, efectos y las consecuencias jurídicas derivadas del acuerdo y el proceso. La orientación que se brinde en este espacio debe conducir a las partes a tomar una decisión autónoma e informada sobre su participación en el programa. b) Tipología: Teniendo en cuenta lo establecido en el sistema de justicia actual, se propone desarrollar una práctica que contemple la adopción de los principios de justicia restaurativa en el mecanismo de la conciliación. c) Componentes: Debe haber claridad en cuanto a objetivos, viabilidad, condiciones de acceso, estrategias de participación de la comunidad, acuerdos de reparación, mecanismos de protección de derechos, estrategias de seguimiento, tiempos de duración del proceso y metodología. El seguimiento que se efectúe debe permitir evaluar periódicamente el proceso y la efectividad del mismo. d) Momento procesal: Se debe tener en cuenta la aplicación del principio de oportunidad y la naturaleza del principio de reparación integral. e) Acuerdos de reparación o estrategias de resarcimiento: Se deben definir claramente los diferentes acuerdos de reparación que contempla la justicia restaurativa, teniendo en cuenta el marco normativo del sistema de justicia actual. Estos acuerdos deben contemplar la reparación económica a la víctima, pero bajo ninguna circunstancia deben reducirse a ella. f) Participantes: Para cada tipología se deben establecer las competencias y funciones de los profesionales y las responsabilidades de las instituciones que hagan parte del proceso.

\section{Criterios para programas de asistencia víctimas $y$ redes de apoyo}

Como parte del programa piloto de Justicia Restaurativa es importante avanzar en la creación de programas de atención a víctimas que contemplen la dimensión psicológica, social y jurídica de los efectos del delito. Estos programas deben hacer parte de redes de apoyo y asistencia psicosocial para víctimas de VIF, las cuales deben estar integradas por instituciones públicas y privadas. Entre otros programas, se deben contemplar a) Programas específicos de apoyo a niños, niñas, adolescentes y adultos mayores víctimas de VIF y b) Programas de apoyo a personas adictas al alcohol o a SPA. Los servicios comunitarios deben hacer parte de esta red. Teniendo en cuenta los efectos jurídicos del proceso restaurativo, principalmente los acuerdos, y la posible continuidad de la convivencia familiar e inserción social del agresor en la comunidad, es fundamental crear programas de apoyo y orientación para los agresores en el seno de la misma red institucional que haya elaborado los programas de asistencia a víctimas.

Los programas de asistencia dirigidos a los familiares de los agresores son fundamentales, tanto por el apoyo psicosocial, como por la prevención del delito. También se debe involucrar activamente a la comunidad, tanto en el proceso de reparación, como en el ejercicio de control social, a través de redes de 
apoyo integradas por instituciones públicas y privadas.

Finalmente, teniendo en cuenta la notable disposición del CAVIF para el desarrollo de programas de justicia restaurativa, así como la red institucional que actualmente opera en él, es importante avanzar en la formulación de programas de apoyo adicionales, tales como: paneles de ayuda para jóvenes, comunidades terapéuticas, círculos de apoyo a víctimas, servicios comunitarios relacionados, programas de capacitación e inserción laboral para víctimas y programas de sensibilización comunitaria, entre otros. Tanto el programa piloto como el programa que se implemente en el CAVIF deben estar sujetos a evaluaciones periódicas, con el fin de medir su impacto en la problemática, los usuarios y la comunidad.

\section{Discusión}

Para el diseño de un programa piloto en justicia restaurativa orientado a casos de violencia intrafamiliar, se debe hacer visible, ante los usuarios y la ciudadanía en general, la misión, los objetivos, servicios y programas de la Fiscalía General de la Nación para abordar los conflictos de violencia intrafamiliar. Esto, debido al poco conocimiento de los usuarios acerca de las alternativas de abordaje jurídico-penal del delito, sus derechos y efectos jurídicos de los acuerdos. En la misma vertiente, es fundamental brindar capacitación a los funcionarios y proveer a la entidad de los recursos humanos, técnicos y físicos para hacer viable un programa de justicia restaurativa en el CAVIF.

Dado el carácter novedoso que supone la participación de la comunidad en el proceso integral de la justicia restaurativa, se debe identificar los criterios y mecanismos de participación de la comunidad, los posibles acuerdos de reparación que la involucran, las estrategias de control social informal que cumple en los procedimientos de justicia y las estrategias de seguimiento y apoyo comunitario, de acuerdo con el marco normativo del sistema de justicia actual.

En este mismo sentido, es importante generar espacios informativos de orientación psicojurídica para víctimas y agresores de VIF que deseen hacer parte del programa. En este ítem se debe suministrar toda la información relacionada con el mecanismo: su definición, principios, procedimientos, objetivos, efectos y consecuencias jurídicas, además de aspectos éticos, psicológicos y sociales. La orientación que se brinde en este espacio debe conducir a las partes a tomar una decisión autónoma e informada sobre su participación en el programa.

Finalmente, el programa que se implemente debe asumir el criterio de abordaje integral de la dimensión psicológica, social y jurídica de los efectos del delito. Este debe contemplar redes de apoyo y asistencia psicosocial para víctimas de VIF, las cuales deben estar integradas por instituciones públicas y privadas. Entre otros programas, es importante desarrollar algunos específicos dirigidos a niños, niñas, adolescentes y adultos mayores víctimas de VIF, y a personas adictas al alcohol o a SPA. Los programas de asistencia a los familiares de los agresores son fundamentales, tanto por el apoyo psicosocial, como por la prevención del delito.

\section{Referencias}

Beristain, A. (1998). Criminología y Victimología. Alternativas Re-creadoras al Delito. Bogotá, Colombia: Leyer.

Beristain, Mesotti y Sampedro (2001). XXII Congreso Mundial de Criminología. Memorias. Río de Janeiro, 22, 23 y 24 de octubre.

Código de Procedimiento Penal Colombiano (2008). Ley 906 de 2004. Bogotá Colombia: LEGIS editores S.A, Séptima edición.

Código de Procedimiento Penal Colombiano (2008). Ley 600 de 2000. Bogotá Colombia: LEGIS editores S.A., Séptima edición.

Comité de ministros del consejo de Europa. (1985). Sobre la posición de la víctima en el marco del Derecho Penal y del proceso penal. Recomendación 4 del 28 de junio de 1985.

Comunicación 349 final. (1999). Sobre víctimas de delitos en la Unión Europea, Normas y Medidas. Comunicación al Parlamento Europeo, al Consejo y al Comité Económico Social, Bruselas, 14 de Julio de 1999.

Confraternidad Carcelaria Internacional (2005), ¿Qué es la Justicia Restaurativa? Trabajo resu- 
men sobre Justicia Restaurativa. Recuperado en Agosto de 2008, de http://www.pfi.org/cjr/spanish/quees/

Congreso de la República (2002). Acto legistalitivo 03 de 2002. Bogotá. Recuperado en diciembre de 2009 en http://www.elabedul.net/Documentos/ Leyes/2002/Acto_legislativo_03.pdf

Declaración de Viena. (2000). Sobre la delincuencia y la justicia: frente a los retos del siglo XXI. Viena, 15 de Abril de 2000.

Fiscalía General de la Nación. (2004). Acuerdo 123 de 2004. Recuperado en Julio de 2008 en http://www.fiscalia.gov.co/pag/entidad/quehacer.html

Fiscalía General de la Nación. (2004). Ley 906 de 2004. Recuperado en Julio de 2008 en http:// www.fiscalia.gov.co/pag/entidad/quehacer.html

Fiscalía General de la Nación. (2005). Manual de procedimientos de Fiscalía en el Sistema Penal Acusatorio Colombiano. Recuperado en Julio de 2008 en http://www.justiciarestaurativa.com/ Documentos/ManualProcedimientoFiscalia.pdf

García-Pablos, A. (1999). Tratado de criminología. Valencia: Tirant lo Blanch.

Libro Verde. (2001). Comunicación 536 final, sobre la indemnización a las víctimas de los delitos. Presentado por la Comisión Europea. Bruselas 2 de Septiembre de 2001.

ONU. (1985). Sobre los principios básicos de justicia para las víctimas del crimen y de abuso de poder. Declaración 40/34, Naciones Unidas 1985. ONU (1999). Delincuentes y victimas: Responsabilidad y equidad en el proceso de justicia penal.
$\mathrm{X}$ Congreso sobre prevención del delito y tratamiento del delincuente de 15 de Diciembre de 1999.

ONU. (2000). Sobre prevención del delito y tratamiento del delincuente, presentado en el informe del X congreso de las Naciones Unidas, 19 de Julio de 2000.

Sampedro, J. (2002). La humanización en el derecho penal. Bogotá: Legis.

Unión Europea (2001). Relativa al estatuto de la víctima en el proceso penal, Decisión marco del consejo de la Unión Europea de 15 de Marzo de 2001. Documento 301F0220, Diario Oficial $\mathrm{N}^{\circ}$ L082 de 22 de Marzo de 2001, p. 0001-0004.

Van Ness, D. y Strong, K. (1997). V. Prevención de la criminalidad. (Documento de referencia). Centro de las Naciones Unidas para los Asentamientos Humanos. Programa Ciudades más Seguras.

Walgrave, L. (1999). La justice restaurative: à la recherche d'une théorie et d'un programme. Criminologie, 32, Belgique.

Walgrave, L. Y Bazemore, G. (1999). Restorative Juvenile Justice: Repairing the Harm of Youth Crime. Monsey, NY: Criminal Justice Press.

Walker, L. (2007). Public health approaches to family maltreatment prevention: Resetting family psychology's sights from the home to the community, Journal of Family Psychology, 22. Recuperado en Agosto de 2008 en http://search. ebscohost.com/login.aspx?direct $=$ true $\& d b=$ pdh $\&$ $\mathrm{AN}=$ fam-22-4-518\&amp;lang $=$ es \& site $=$ ehost live

Artículo recibido: 08/12/2009

Revisión recibida: 04/01/2010

Artículo aceptado: 11/01/2010 